\title{
Role of the kallikrein-kinin system in traumatic brain injury
}

\author{
Christiane Albert-Weissenberger ${ }^{1}{ }^{*}$, Stine Mencl ${ }^{1}$, Sarah Hopp ${ }^{1}$, Christoph Kleinschnitz ${ }^{1 \dagger}$ \\ and Anna-Leena Sirén ${ }^{2 \dagger}$
}

' Department of Neurology, University Hospital of Würzburg, Würzburg, Germany

${ }^{2}$ Department of Neurosurgery, University Hospital of Würzburg, Würzburg, Germany

Edited by:

Arthur Liesz, University Hospital

Munich, Germany

Reviewed by:

Nikolaus Plesnila,

Ludwig-Maximilians-University of

Munich, Germany

Tim Magnus, Universität Hamburg Germany

${ }^{*}$ Correspondence:

Christiane Albert-Weissenberger, Department of Neurology,

University Hospital of Würzburg,

Josef-Schneider-Str. 11, 97080

Würzburg, Germany

e-mail:Albert_c2@ukw.de

${ }^{\dagger}$ These authors have contributed equally to this work.
Traumatic brain injury (TBI) is a major cause of mortality and morbidity worldwide. Despite improvements in acute intensive care, there are currently no specific therapies to ameliorate the effects of TBI. Successful therapeutic strategies for TBI should target multiple pathophysiologic mechanisms that occur at different stages of brain injury. The kallikrein-kinin system is a promising therapeutic target for TBI as it mediates key pathologic events of traumatic brain damage, such as edema formation, inflammation, and thrombosis. Selective and specific kinin receptor antagonists and inhibitors of plasma kallikrein and coagulation factor XII have been developed, and have already shown therapeutic efficacy in animal models of stroke and TBI. However, conflicting preclinical evaluation, as well as limited and inconclusive data from clinical trials in TBI, suggests that caution should be taken before transferring observations made in animals to humans. This review summarizes current evidence on the pathologic significance of the kallikrein-kinin system during $\mathrm{TBI}$ in animal models and, where available, the experimental findings are compared with human data.

\section{Keywords: traumatic brain injury, kallikrein-kinin system, bradykinin, factor XII, kinin receptor}

\section{INTRODUCTION}

Traumatic brain injury (TBI) accounts for one-third of all injuryrelated deaths. An estimated 1.74 million TBIs occur annually in the United States (Faul et al., 2010; Ma et al., 2014). About $43 \%$ of people discharged with TBI after acute hospitalization, develop TBI-related long-term disability. Moreover, individuals with a history of TBI are more likely to receive welfare or disability payments and to develop neurologic disorders that are disabling in their own right (Ma et al., 2014) - for example, Alzheimer's disease (Fleminger et al., 2003). The incidence of TBI is particularly high in younger age groups, with motor vehicle accidents being the leading cause (Asemota et al., 2013). The direct costs of TBI have been estimated at $\$ 13.1$ billion per year (in 2013) in the United States (Ma et al., 2014); additionally, $\$ 64.7$ billion per year are lost through missed work and lost productivity, and total medical costs range from $\$ 63.4$ to $\$ 79.1$ billion per year (Ma et al., 2014). The significant economic impact of TBI is at variance with the lack of therapies available to ameliorate the effects of TBI.

To better understand the pathobiology of TBI and to evaluate potential therapeutic approaches, various animal models have been developed to mimic certain components of clinical TBI. Closed-head weight-drop models - with a weight that falls onto the exposed skull—probably mimic most closely clinical TBI cases. Depending on the experimental settings, the impact of the weight results in largely focal or diffuse brain injury. In controlled cortical impact models an impact onto the dura, inflicted by a pneumatic pistol, predominantly results in focal brain injury. For fluid percussion models it is inconsistently reported to what extend the brain injury is diffuse or focal. Here, tissue damage is induced by a fluid pulse onto the intact dura through a craniotomy. A solely focal brain injury can be achieved by cold lesion models, which commonly utilize a cold rod that is exposed to the dura or skull (for a comprehensive review, see AlbertWeissenberger and Sirén, 2010). Despite promising results from these experimental TBI models, more than 30 phase III trials of TBI in humans have failed to generate favorable results in terms of developing potential therapeutic strategies (Doppenberg et al., 2004; Maas et al., 2010). In part, these failures likely reflect the heterogeneity of TBI (e.g., severity and location of the injury - focal vs. diffuse injury). Therefore, future therapeutic approaches are more likely to succeed if they target diverse pathophysiologic mechanisms. As the kallikrein-kinin system links edema formation, inflammation, and thrombosis (Costa-Neto et al., 2008; Langhauser et al., 2012), it seems to be a promising target.

In this review, current available evidence on the pathologic significance of the kallikrein-kinin system during TBI is summarized. Findings from experimental models are compared with human data, where available.

\section{THE KALLIKREIN-KININ SYSTEM}

Kinins play key roles in regulating vascular permeability and inflammatory processes following tissue injury (Leeb-Lundberg et al., 2005). They are released either by the tissue or the plasma. In the tissue, kallikrein is activated by proteases and it releases a kinin called kallidin from the inactive precursors, the kininogens. Plasma kallikrein is released from prekallikrein by activated factor XII (FXII) and reciprocally activates FXII (Revak et al., 1978). Subsequently, plasma kallikrein releases bradykinin from 


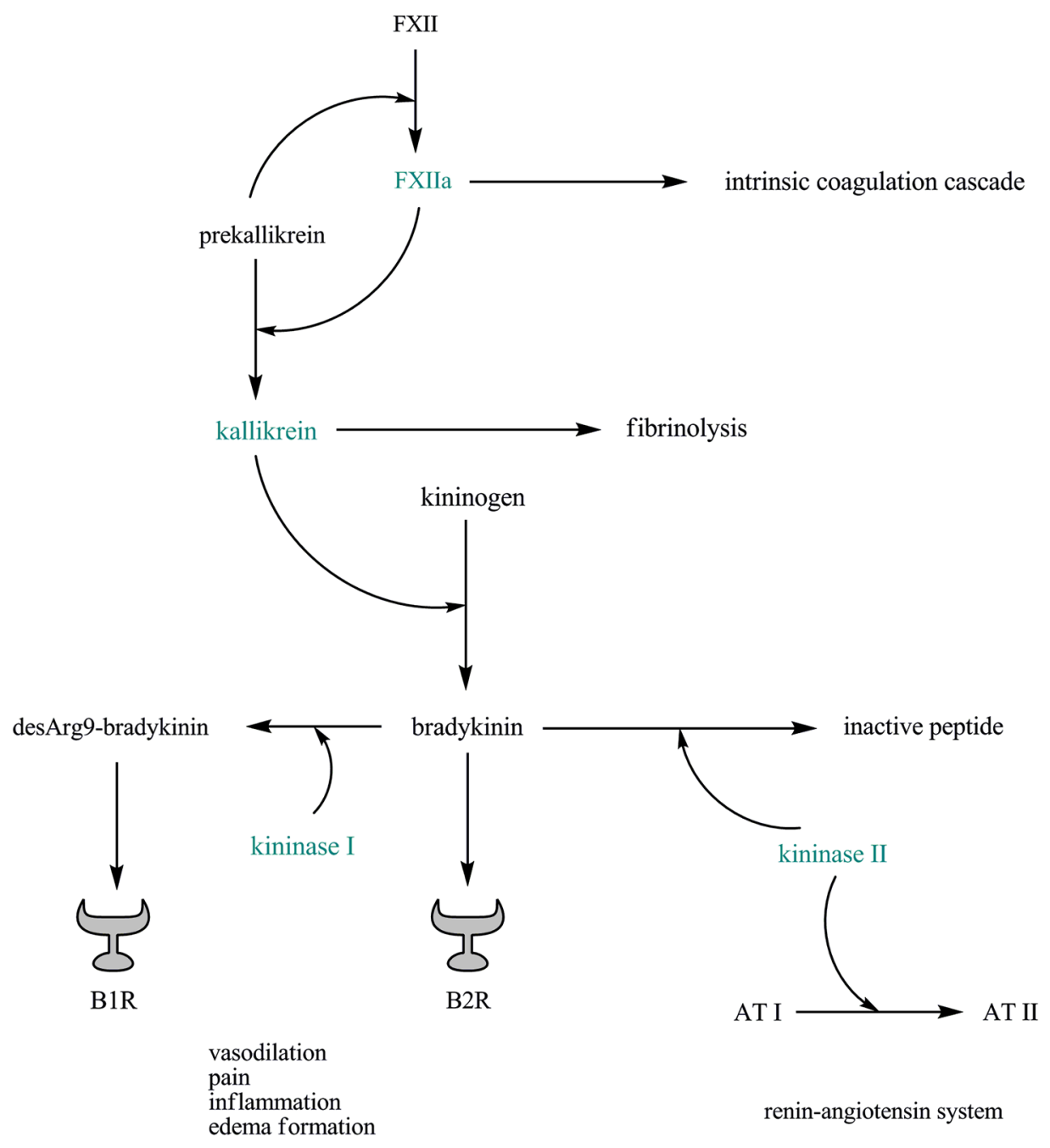

FIGURE 1 | The plasma kallikrein-kinin system is linked to thrombosis, fibrinolysis, and the renin-angiotensin system. Abbreviations: AT, angiotensin; B1R, kinin receptor B1; B2R, kinin receptor B2; FXII, factor XII; FXIla, activated factor XII.

the kininogens. Kallidin and bradykinin mediate their effects via kinin receptor B2. Both kallidin and bradykinin are converted by the action of kininase I-type carboxypeptidases into des-Arg9bradykinin and des-Arg10-kallidin, respectively, which specifically bind to kinin receptor B1 (Figure 1).

Interestingly, the plasma kallikrein-kinin system is linked to thrombosis, fibrinolysis, and the renin-angiotensin system: FXII has an essential role in thrombosis (Renné et al., 2012), and mice selectively depleted of plasma kallikrein or FXII are protected from pathogenic thrombus formation without increased risk of bleeding (Revenko et al., 2011). Plasma kallikrein (and, to a lesser extent, activated FXII) converts plasminogen to plasmin, linking the kallikrein-kinin system to fibrinolysis (Colman, 1969). In addition, bradykinin is mainly inactivated by kininase II (also known as angiotensin converting enzyme (ACE)), an enzyme that also degrades angiotensin I into angiotensin II (Bernstein et al., 2011; Figure 1).

\section{ROLE OF THE KININ RECEPTORS IN TRAUMATIC BRAIN INJURY}

All essential components of the kallikrein-kinin system are present in the rodent and human brain (Kariya et al., 1985; Kizuki et al., 1994; Ongali et al., 2003; Trabold et al., 2010). Moreover, it has been reported that their expression is induced after brain injury but the expression pattern varies depending on the brain injury model used (Ongali et al., 2006; Raslan et al., 2010; Trabold et al., 2010; Albert-Weissenberger et al., 2012). In a controlled cortical impact model, bradykinin concentrations in the brain were significantly increased at $2 \mathrm{~h}$ post-injury, and then subsequently declined (Trabold et al., 2010). Kinin receptor B1 transcripts peaked at $6 \mathrm{~h}$ post-injury and remained elevated until day 2, whereas kinin receptor B2 was constitutively expressed at lower levels (Trabold et al., 2010). In a cold lesion model, a strong but transient mRNA expression of kinin receptor B1 was observed in the first $12 \mathrm{~h}$ after injury, whereas the enhanced 
mRNA expression of kinin receptor B2 was more sustained, lasting up to $48 \mathrm{~h}$ (Raslan et al., 2010). In our hand, a closed-head weight-drop trauma in mice resulting in a mixed brain injury pattern (focal and diffuse brain injury) caused a slight increase of kinin receptor mRNA levels one week after injury induction (Albert-Weissenberger et al., 2012).

Kinins mediate their physiologic effects via kinin receptors B1 and B2. Support for a pathologic role of kinin receptors in TBI was obtained through the use of genetically engineered mice that lack either kinin receptor $\mathrm{B} 1$ or kinin receptor $\mathrm{B} 2$. After controlled cortical impact, kinin receptor B2-deficient mice, but not kinin receptor B1-deficient mice, had less brain edema, smaller lesion volumes, and a better functional outcome as compared with wild-type mice (Trabold et al., 2010). Another study also reported that the kinin receptor B2 mediates detrimental effects after TBI in mice (Hellal et al., 2003). On the contrary, findings from our group point out that kinin receptor B1 plays an important role in the pathophysiology of TBI (Raslan et al., 2010). Kinin receptor B1-deficient mice subjected to cold lesion displayed smaller lesion volumes, less blood-brain barrier disruption, and less inflammation in the injured brain area, whereas kinin receptor B2-deficient mice were fully susceptible to brain trauma. Supporting these results, application of the kinin receptor B1-inhibitor R-715 reduced lesion size even in a therapeutic setting (administered $1 \mathrm{~h}$ after injury induction), whereas application of the kinin receptor B2-inhibitor Hoe140 (Icatibant) had no significant effect on lesion volume in wildtype mice (Raslan et al., 2010). Importantly, application of the kinin receptor B2-inhibitor Hoe140 in kinin receptor B1-deficient mice had no additive benefit on the reduction in brain lesion size. However, Hoe140 treatment has been shown to result in a moderate reduction in brain lesion size after cold lesion in rats and mice (by 19\% and 14\%, respectively) (Görlach et al., 2001). We recently reported that kinin receptor B1 deficiency in mice is associated with diminished functional deficits and a reduction in axonal injury, astrogliosis, and neuronal apoptosis after a weightdrop-induced brain trauma (Albert-Weissenberger et al., 2012). Inhibition of kinin receptor B1 in wild-type mice by the specific kinin receptor B1-blocker $\mathrm{R}-715$, starting from $1 \mathrm{~h}$ after trauma, confirmed these results. By contrast, deficiency of kinin receptor B2 was ineffective in this trauma model (Albert-Weissenberger et al., 2012).

Kinin receptor inhibitors, other than the kinin receptor B1inhibitor R-715 and the kinin receptor B2-inhibitor Hoe140, have also been tested in experimental and clinical settings of TBI. Treatment with the kinin receptor B2-antagonist LF 18-1505T resulted in reduced brain edema and improved neurologic outcome in a closed-head trauma model in rats (Ivashkova et al., 2006). In rats subjected to closed-head trauma, a continuous infusion of the nonpeptide kinin receptor B2-inhibitor LF 16-0687 (Anatibant), from $1 \mathrm{~h}$ to $24 \mathrm{~h}$ after injury, resulted in diminished brain edema formation on day 1 and less neurologic deficits on day 1, day 3, and day 7 (Pruneau et al., 1999). Administered as a single dose $1 \mathrm{~h}$ after trauma, LF 16-0687 was able to reduce brain swelling and to improve the recovery of neurologic function following closed-head trauma in rats (Kaplanski et al., 2002). Similar results were obtained after controlled cortical impact or cold lesion (Schulz et al., 2000; Stover et al., 2000; Zweckberger and Plesnila, 2009). It was suggested that stabilization of the blood-brain barrier and mitigation of inflammatory processes are the underlying mechanisms. However, it remains questionable whether LF 16-0687 is effective within a clinically relevant time window (Plesnila et al., 2001). LF 16-0687 was investigated in a phase I clinical study (Marmarou et al., 2005) in patients with severe TBI. In this trial, patients with TBI and Glasgow Coma Scale $<8$ received LF $16-0687$ as a single subcutaneous injection within $8-12 \mathrm{~h}$ after TBI, and Marmarou et al. concluded that LF 16-0687 provides a potential therapeutic approach to treating cerebral edema following brain damage, as the compound was well tolerated. A phase II trial using LF 16-0687 in TBI patients with a Glasgow Coma Scale score of $\leq 12$ was unable to recruit a sufficient number of patients (Shakur et al., 2009). Moreover, results from this trial were disappointing in that there was a non-significant trend towards worse outcomes in the LF 16-0687 treatment group.

Bradycor (Deltibant, CP-0127), a peptide compound kinin receptor B2-antagonist, was tested in a pilot, single-blinded clinical pilot study in 20 patients with focal head injury. Results indicated that CP-0127 treatment diminished the pathologic rise of intracranial pressure (Narotam et al., 1998). A phase II trial in severely brain injured patients reported a slight trend towards a better outcome in the CP-0127 treatment group (Marmarou et al., 1999). However, a Cochrane analysis concluded that those clinical trials do not provide reliable evidence that kinin receptor B2-antagonists are effective in improving outcome after TBI (Ker and Blackhall, 2008). Reports on the clinical use of kinin receptor B1-inhibitors in patients with TBI are not yet available.

\section{ROLE OF THE KALLIKREINS AND FACTOR XII IN TRAUMATIC BRAIN INJURY}

In 1978, it was reported that patients with severe trauma have increased protease activity in the cerebrospinal fluid, the activity of which could be inhibited by aprotinin treatment. In rabbits subjected to cold injury, aprotinin treatment resulted in reduced brain edema formation (Unterberg et al., 1986). Aprotinin is known to inhibit several serine proteases, including plasma kallikrein, and a reduced protease activity has been associated with a lower mortality rate (Auer et al., 1979).

There are promising results from recent studies suggesting a therapeutic potential for the serine protease inhibitor C1inhibitor. C1-inhibitor is an endogenous regulator with various physiologic functions (Singer and Jones, 2011), including the inhibition of activated FXII and plasma kallikrein. Application of C1-inhibitor has proven to be beneficial in ischemic stroke (Heydenreich et al., 2012). Similarly, in mice subjected to controlled cortical impact, C1-inhibitor treatment at $10 \mathrm{~min}$ (Longhi et al., 2008) or $1 \mathrm{~h}$ (Longhi et al., 2009) after injury resulted in less pronounced functional deficits and smaller brain lesions compared with control mice.

\section{ROLE OF THE KININASE II IN TRAUMATIC BRAIN INJURY}

Indirect support for a pathologic role of kinins in TBI was obtained through inhibition of kininase II, an enzyme that 
hydrolyzes proteins such as bradykinin, substance $\mathrm{P}$, and angiotensin I. Inhibition of kininase II results in downregulation of angiotensin II production. Moreover, it has been reported that kininase II inhibition potentiates the physiologic effects of kinins and all kinin-related peptides are subject to less hydrolyzation. Using the kininase II inhibitor Captopril, Harford-Wright et al. (2010) showed, in a diffuse TBI model, that inhibition of kininase II results in increased "dark cell changes" and in exacerbated motor function deficits. However, they did not consider the effects of kininase II inhibition on the kallikrein-kinin system; instead, the authors conclude that kininase II inhibitors worsen outcome following TBI, presumably because they impair the degradation of substance $\mathrm{P}$-as shown by the increase in substance $\mathrm{P}$ immunoreactivity. However, the fact that bradykinin potentiates the release of substance $\mathrm{P}$ should also be noted (for a review, see Geppetti, 1993). Interestingly, a kininase II polymorphism in humans influences the neuropsychologic subacute performance of patients with moderate or severe TBI (Ariza et al., 2006).

\section{PERSPECTIVE}

There is accumulating evidence that the kallikrein-kinin system is critically involved in various brain diseases (e.g., stroke, multiple sclerosis, Alzheimer's disease, epilepsy, depression) and its modulation might be a promising strategy to combat these diseases. The reported effects of specific components of the kallikrein-kinin system, however, are often inconsistent.

The paucity of therapies for brain trauma has resulted in a pressing clinical demand for new treatment options. The findings summarized in this review indicate that modulation of the components of the kallikrein-kinin system, which links edema formation, inflammation, and thrombosis, might be a promising strategy to combat TBI. Another tempting approach might be inhibition of the starting point of the kallikrein-kinin system, e.g., by the C1-inhibitor.

\section{AUTHOR CONTRIBUTIONS}

Christiane Albert-Weissenberger wrote the manuscript. Stine Mencl corrected the manuscript and checked the references. Sarah Hopp corrected the manuscript and build the figure. Christoph Kleinschnitz revised the manuscript for important intellectual content and approved the final version of the manuscript. AnnaLeena Sirén revised the manuscript critically for important intellectual content and approved the final version of the manuscript.

\section{ACKNOWLEDGMENTS}

Part of the work referenced in this review article was supported by the Else Kröner-Fresenius Foundation, the Interdisciplinary Center for Clinical Research (IZKF) Würzburg (Project A226), the Deutsche Forschungsgemeinschaft (SFB 688) and CSL Behring GmbH, Marburg, Germany.

\section{REFERENCES}

Albert-Weissenberger, C., and Sirén, A. L. (2010). Experimental traumatic brain injury. Exp. Transl. Stroke Med. 2:16. doi: 10.1186/2040-7378-2-16

Albert-Weissenberger, C., Stetter, C., Meuth, S. G., Göbel, K., Bader, M., Sirén, A. L., et al. (2012). Blocking of bradykinin receptor B1 protects from focal closed head injury in mice by reducing axonal damage and astroglia activation. J. Cereb. Blood Flow Metab. 32, 1747-1756. doi: 10.1038/jcbfm.2012.62
Ariza, M., Matarin, M. D., Junqué, C., Mataró, M., Clemente, I., Moral, P., et al. (2006). Influence of Angiotensin-converting enzyme polymorphism on neuropsychological subacute performance in moderate and severe traumatic brain injury. J. Neuropsychiatry Clin. Neurosci. 18, 39-44. doi: 10.1176/appi. neuropsych.18.1.39

Asemota, A. O., George, B. P., Bowman, S. M., Haider, A. H., and Schneider, E. B. (2013). Causes and trends in traumatic brain injury for United States adolescents. J. Neurotrauma 30, 67-75. doi: 10.1089/neu.2012.2605

Auer, L. M., Marth, E., Heppner, F., and Holasek, A. (1979). Proteolytic enzyme activity in patienst with severe head injury and the effect of a proteinase inhibitor. Acta Neurochir. (Wien) 49, 207-217. doi: 10.1007/bf01808960

Bernstein, K. E., Shen, X. Z., Gonzalez-Villalobos, R. A., Billet, S., Okwan-Duodu, D., Ong, F. S., et al. (2011). Different in vivo functions of the two catalytic domains of angiotensin-converting enzyme (ACE). Curr. Opin. Pharmacol. 11, 105-111. doi: 10.1016/j.coph.2010.11.001

Colman, R. W. (1969). Activation of plasminogen by human plasma kallikrein. Biochem. Biophys. Res. Commun. 35, 273-279. doi: 10.1016/0006$291 x(69) 90278-2$

Costa-Neto, C. M., Dillenburg-Pilla, P., Heinrich, T. A., Parreiras-e-Silva, L. T., Pereira, M. G., Reis, R. I., et al. (2008). Participation of kallikrein-kinin system in different pathologies. Int. Immunopharmacol. 8, 135-142. doi: 10.1016/j.intimp. 2007.08.003

Doppenberg, E. M., Choi, S. C., and Bullock, R. (2004). Clinical trials in traumatic brain injury: lessons for the future. J. Neurosurg. Anesthesiol. 16, 87-94. doi: 10. 1097/00008506-200401000-00019

Faul, M., Xu, L., Wald, M. M., and Coronado, V. G. (2010). Traumatic Brain Injury in the United States: Emergency Department Visits, Hospitalizations and Deaths, 2002-2006. Atlanta: U.S. Department of Health and Human Services, Centers for Disease Control and Prevention, National Center for Injury Prevention and Control.

Fleminger, S., Oliver, D. L., Lovestone, S., Rabe-Hesketh, S., and Giora, A. (2003). Head injury as a risk factor for Alzheimer's disease: the evidence 10 years on; a partial replication. J. Neurol. Neurosurg. Psychiatry 74, 857-862. doi: 10. 1136/jnnp.74.7.857

Geppetti, P. (1993). Sensory neuropeptide release by bradykinin: mechanisms and pathophysiological implications. Regul. Pept. 47, 1-23. doi: 10.1016/01670115(93)90268-d

Görlach, C., Hortobágyi, T., Hortobágyi, S., Benyó, Z., Relton, J., Whalley, E. T., et al. (2001). Bradykinin B2, but not B1, receptor antagonism has a neuroprotective effect after brain injury. J. Neurotrauma 18, 833-838. doi: 10 . 1089/089771501316919193

Harford-Wright, E., Thornton, E., and Vink, R. (2010). Angiotensin-converting enzyme (ACE) inhibitors exacerbate histological damage and motor deficits after experimental traumatic brain injury. Neurosci. Lett. 481, 26-29. doi: 10. 1016/j.neulet.2010.06.044

Hellal, F., Pruneau, D., Palmier, B., Faye, P., Croci, N., Plotkine, M., et al. (2003). Detrimental role of bradykinin B2 receptor in a murine model of diffuse brain injury. J. Neurotrauma 20, 841-851. doi: 10.1089/089771503322385773

Heydenreich, N., Nolte, M. W., Göb, E., Langhauser, F., Hofmeister, M., Kraft, P., et al. (2012). C1-inhibitor protects from brain ischemia-reperfusion injury by combined antiinflammatory and antithrombotic mechanisms. Stroke 43, $2457-$ 2467. doi: $10.1161 /$ strokeaha.112.660340

Ivashkova, Y., Svetnitsky, A., Mayzler, O., Pruneau, D., Benifla, M., Fuxman, Y., et al. (2006). Bradykinin B2 receptor antagonism with LF 18-1505T reduces brain edema and improves neurological outcome after closed head trauma in rats. $J$. Trauma 61, 879-885. doi: 10.1097/01.ta.0000234722.98537.01

Kaplanski, J., Pruneau, D., Asa, I., Artru, A. A., Azez, A., Ivashkova, Y., et al. (2002). LF 16-0687 Ms, a bradykinin B2 receptor antagonist, reduces brain edema and improves long-term neurological function recovery after closed head trauma in rats. J. Neurotrauma 19, 953-964. doi: 10.1089/0897715023203 17104

Kariya, K., Yamauchi, A., and Sasaki, T. (1985). Regional distribution and characterization of kinin in the CNS of the rat. J. Neurochem. 44, 1892-1897. doi: 10. 1111/j.1471-4159.1985.tb07185.x

Ker, K., and Blackhall, K. (2008). Beta-2 receptor antagonists for acute traumatic brain injury. Cochrane Database Syst. Rev. 23:CD006686. doi: 10. 1002/14651858.cd006686.pub2

Kizuki, K., Suzuki, T., Sugaya, K., Noguchi, T., and Kudo, M. (1994). Tissue kallikrein in rat and mouse neurons. Braz. J. Med. Biol. Res. 27, 1891-1896. 
Langhauser, F., Göb, E., Kraft, P., Geis, C., Schmitt, J., Brede, M., et al. (2012). Kininogen deficiency protects from ischemic neurodegeneration in mice by reducing thrombosis, blood-brain barrier damage and inflammation. Blood 120, 4082-4092. doi: 10.1182/blood-2012-06-440057

Leeb-Lundberg, L. M., Marceau, F., Müller-Esterl, W., Pettibone, D. J., and Zuraw, B. L. (2005). International union of pharmacology. XLV. Classification of the kinin receptor family: from molecular mechanisms to pathophysiological consequences. Pharmacol. Rev. 57, 27-77. doi: 10.1124/pr.57.1.2

Longhi, L., Perego, C., Ortolano, F., Zanier, E. R., Bianchi, P., Stocchetti, N., et al. (2009). C1-inhibitor attenuates neurobehavioral deficits and reduces contusion volume after controlled cortical impact brain injury in mice. Crit. Care Med. 37, 659-665. doi: 10.1097/ccm.0b013e318195998a

Longhi, L., Perego, C., Zanier, E. R., Ortolano, F., Bianchi, P., Stocchetti, N., et al. (2008). Neuroprotective effect of C1-inhibitor following traumatic brain injury in mice. Acta Neurochir. Suppl. 102, 381-384. doi: 10.1007/978-3-211-85578$2 \_73$

Ma, V. Y., Chan, L., and Carruthers, K. J. (2014). Incidence, prevalence, costs and impact on disability of common conditions requiring rehabilitation in the United States: stroke, spinal cord injury, traumatic brain injury, multiple sclerosis, osteoarthritis, rheumatoid arthritis, limb loss and back pain. Arch. Phys. Med. Rehabil. 95, 986.e1-995.e1. doi: 10.1016/j.apmr.2013.10.032

Maas, A. I., Roozenbeek, B., and Manley, G. T. (2010). Clinical trials in traumatic brain injury: past experience and current developments. Neurotherapeutics 7, 115-126. doi: 10.1016/j.nurt.2009.10.022

Marmarou, A., Guy, M., Murphey, L., Roy, F., Layani, L., Combal, J. P., et al. (2005). A single dose, three-arm, placebo-controlled, phase I study of the bradykinin B2 receptor antagonist Anatibant (LF16-0687Ms) in patients with severe traumatic brain injury. J. Neurotrauma 22, 1444-1455. doi: 10.1089/neu.2005.22.1444

Marmarou, A., Nichols, J., Burgess, J., Newell, D., Troha, J., Burnham, D., et al. (1999). Effects of the bradykinin antagonist Bradycor (deltibant, CP-1027) in severe traumatic brain injury: results of a multi-center, randomized, placebocontrolled trial. American Brain Injury Consortium Study Group. J. Neurotrauma 16, 431-444. doi: 10.1089/neu.1999.16.431

Narotam, P. K., Rodell, T. C., Nadvi, S. S., Bhoola, K. D., Troha, J. M., Parbhoosingh, R., et al. (1998). Traumatic brain contusions: a clinical role for the kinin antagonist CP-0127. Acta Neurochir. (Wien) 140, 793-802; discussion 802-803. doi: 10.1007/s007010050181

Ongali, B., Campos, M. M., Bregola, G., Rodi, D., Regoli, D., Thibault, G., et al. (2003). Autoradiographic analysis of rat brain kinin B1 and B2 receptors: normal distribution and alterations induced by epilepsy. J. Comp. Neurol. 461, 506-519. doi: 10.1002/cne.10706

Ongali, B., Hellal, F., Rodi, D., Plotkine, M., Marchand-Verrecchia, C., Pruneau, D., et al. (2006). Autoradiographic analysis of mouse brain kinin B1 and B2 receptors after closed head trauma and ability of Anatibant mesylate to cross the blood-brain barrier. J. Neurotrauma 23, 696-707. doi: 10.1089/neu.2006.23.696

Plesnila, N., Schulz, J., Stoffel, M., Eriskat, J., Pruneau, D., and Baethmann, A. (2001). Role of bradykinin B2 receptors in the formation of vasogenic brain edema in rats. J. Neurotrauma 18, 1049-1058. doi: 10.1089/08977150152693746

Pruneau, D., Chorny, I., Benkovitz, V., Artru, A., Roitblat, L., and Shapira, Y. (1999). Effect of LF 16-0687MS, a new nonpeptide bradykinin B2 receptor antagonist, in a rat model of closed head trauma. J. Neurotrauma 16, 1057-1065. doi: 10.1089/neu.1999.16.1057

Raslan, F., Schwarz, T., Meuth, S. G., Austinat, M., Bader, M., Renné, T., et al. (2010). Inhibition of bradykinin receptor B1 protects mice from focal brain injury by reducing blood-brain barrier leakage and inflammation. J. Cereb. Blood Flow Metab. 30, 1477-1486. doi: 10.1038/jcbfm.2010.28
Renné, T., Schmaier, A. H., Nickel, K. F., Blombäck, M., and Maas, C. (2012). In vivo roles of factor XII. Blood 120, 4296-4303. doi: 10.1182/blood-2012-07-292094

Revak, S. D., Cochrane, C. G., Bouma, B. N., and Griffin, J. H. (1978). Surface and fluid phase activities of two forms of activated Hageman factor produced during contact activation of plasma. J. Exp. Med. 147, 719-729. doi: 10.1084/jem.147.3. 719

Revenko, A. S., Gao, D., Crosby, J. R., Bhattacharjee, G., Zhao, C., May, C., et al. (2011). Selective depletion of plasma prekallikrein or coagulation factor XII inhibits thrombosis in mice without increased risk of bleeding. Blood 118, 53025311. doi: 10.1182/blood-2011-05-355248

Schulz, J., Plesnila, N., Eriskat, J., Stoffel, M., Pruneau, D., and Baethmann, A. (2000). LF16-0687 a novel non-peptide bradykinin B2 receptor antagonist reduces vasogenic brain edema from a focal lesion in rats. Acta Neurochir. Suppl. 76, 137-139. doi: 10.1007/978-3-7091-6346-7_28

Shakur, H., Andrews, P., Asser, T., Balica, L., Boeriu, C., Quintero, J. D., et al. (2009). The BRAIN TRIAL: a randomised, placebo controlled trial of a Bradykinin B2 receptor antagonist (Anatibant) in patients with traumatic brain injury. Trials 10:109. doi: 10.1186/1745-6215-10-109

Singer, M., and Jones, A. M. (2011). Bench-to-bedside review: the role of C1esterase inhibitor in sepsis and other critical illnesses. Crit. Care 15:203. doi: 10. $1186 /$ cc9304

Stover, J. F., Dohse, N. K., and Unterberg, A. W. (2000). Bradykinin 2 receptor antagonist LF 16-0687Ms reduces posttraumatic brain edema. Acta Neurochir. Suppl. 76, 171-175. doi: 10.1007/978-3-7091-6346-7_34

Trabold, R., Erös, C., Zweckberger, K., Relton, J., Beck, H., Nussberger, J., et al. (2010). The role of bradykinin $\mathrm{B}(1)$ and $\mathrm{B}(2)$ receptors for secondary brain damage after traumatic brain injury in mice. J. Cereb. Blood Flow Metab. 30, 130-139. doi: 10.1038/jcbfm.2009.196

Unterberg, A., Dautermann, C., Baethmann, A., and Müller-Esterl, W. (1986). The kallikrein-kinin system as mediator in vasogenic brain edema. Part 3: Inhibition of the kallikrein-kinin system in traumatic brain swelling. J. Neurosurg. 64, 269276. doi: 10.3171/jns.1986.64.2.0269

Zweckberger, K., and Plesnila, N. (2009). Anatibant, a selective non-peptide bradykinin B2 receptor antagonist, reduces intracranial hypertension and histopathological damage after experimental traumatic brain injury. Neurosci. Lett. 454, 115-117. doi: 10.1016/j.neulet.2009.02.014

Conflict of Interest Statement: The Review Editor Dr. Tim Magnus declares that, despite having collaborated with the author Dr. Christoph Kleinschnitz, the review process was handled objectively and no conflict of interest exists. The authors declare that the research was conducted in the absence of any commercial or financial relationships that could be construed as a potential conflict of interest.

Received: 31 July 2014; accepted: 06 October 2014; published online: 03 November 2014.

Citation: Albert-Weissenberger C, Mencl S, Hopp S, Kleinschnitz C and Sirén A-L (2014) Role of the kallikrein-kinin system in traumatic brain injury. Front. Cell. Neurosci. 8:345. doi: 10.3389/fncel.2014.00345

This article was submitted to the journal Frontiers in Cellular Neuroscience.

Copyright (C) 2014 Albert-Weissenberger, Mencl, Hopp, Kleinschnitz and Sirén. This is an open-access article distributed under the terms of the Creative Commons Attribution License (CC BY). The use, distribution and reproduction in other forums is permitted, provided the original author(s) or licensor are credited and that the original publication in this journal is cited, in accordance with accepted academic practice. No use, distribution or reproduction is permitted which does not comply with these terms. 